\title{
PROCESSO DE DESENVOLVIMENTO DE UM JOGO DIGITAL PARA A APRENDIZAGEM DE CONTEÚDOS DE MATEMÁTICA
}

Gabriel Marchizelli Godinho, Carolina Garcete Serrano, William Henoch Alves Pereira Sidinei de Oliveira Sousa, Monica Fürkotter.

Universidade do Oeste Paulista - UNOESTE, Curso Superior de Tecnologia em Jogos Digitais e Programa de Pósgraduação em Educação, Presidente Prudente, SP. E-mail: gmg0131@hotmail.com

\section{RESUMO}

Este estudo de caráter qualitativo, vinculado a uma pesquisa do PROBIC/Unoeste, busca investigar o potencial de um Jogo Digital Educativo para a aprendizagem de conteúdos matemáticos atemática necessários no desenvolvimento da disciplina Cálculo Diferencial e Integral, visando contribuir com o desempenho dos estudantes dessa disciplina. Para o desenvolvimento do estudo considerou-se quatro etapas: planejamento do jogo, definindo requisitos técnicos e pedagógicos a serem contemplados em seu desenvolvimento, implementação de um protótipo, levantamento de dados referentes às interações dos professores de Cálculo Diferencial e Integral com o jogo e análise dos dados coletados para subsidiar o seu aprimoramento. A apropriação dos recursos de desenvolvimento de jogos possibilitou a criação de artefatos fundamentais como a interface por meio da qual o jogador terá acesso ao ambiente em que se desenrolará a jogabilidade e a modelagem dos objetos 3D do cenário, visando a imersão do estudante no jogo, fundamental para a aprendizagem.

Palavras-chave: jogo digital educativo, aprendizagem de conteúdos de Matemática, motivação, entretenimento, imersão.

\section{DEVELOPMENT PROCESS OF A DIGITAL GAME AIMING THE LEARNING OF MATHEMATICS CONTENTS}

\begin{abstract}
This qualitative study, linked to a research project of the Scientific Initiation Scholarship Program (PROBIC) of Unoeste, seeks to investigate the potential of a Educational Digital Game for the learning of Mathematics contents of Elementary and Secondary Education necessary for the development of the discipline Differential and Integral Calculus, aiming to contribute to the performance of the students of this discipline. For the development of the study, four stages were considered: game planning, defining the technical and pedagogical requirements that should be contemplated in its development, implementation of a game prototype, data collection on the interactions of Differential and Integral Calculus teachers with the game and analysis of the collected data to subsidize the improvement of the game. The appropriation of game development resources allowed the creation of fundamental artifacts such as the interface through which the player will have access to the environment in which the gameplay will unfold and the modeling of the 3D objects of the scenario, aiming to immerse the student in the game, indispensable for learning.
\end{abstract}

Keywords: educational digital game, learning Mathematics contents, motivation, entertainment, immersion. 


\section{INTRODUÇÃO}

A evasão de estudantes nos cursos superiores na área de Ciências Exatas é um problema complexo. Em muitos cursos o número de concluintes é significativamente menor que o número de ingressantes. É também significativo o contingente de estudantes que levam mais que o tempo mínimo de integralização de créditos para concluir o curso.

Tanto a evasão quanto o tempo de permanência no curso são influenciados por fatores institucionais e acadêmicos, vocacionais, sócio-econômicos, pessoais, familiares e de saúde. Interferem também as formas de ingresso, as instituições de ensino serem públicas ou privadas, 0 sexo do estudante e se a instituição oferta ou não pós-graduação (HOED, 2016).

Em levantamento feito sobre as causas de evasão nos cursos de Computação da Universidade de Brasília, os estudantes evadidos indicaram como uma das causas para a evasão a falta de base em conteúdos de Matemática do Ensino Médio (HOED, 2016).

Relatos de professores que atuam em disciplinas iniciais de cursos superiores na área de Ciências Exatas confirmam esse fato destacando o quanto as deficiências na formação matemática básica dos estudantes dificulta o desenvolvimento da disciplina Cálculo Diferencial e Integral e de outras disciplinas que dela dependem diretamente. Merecem destaque as dificuldades dos estudantes com funções, frações, fatoração e manipulações algébricas.

Tais resultados remetem a reflexões sobre o ensino e a aprendizagem de Matemática e a natureza do conhecimento matemático, que difere em vários aspectos dos outros tipos de conhecimento. Uma diferença é o caráter de abstração maior que em qualquer outro conteúdo. Além disso, o conhecimento matemático depende de uma linguagem específica e formal, bastante diferente da linguagem natural. Há uma polêmica entre aqueles que têm uma concepção bastante restritiva da linguagem matemática, priorizando sua função formal, enquanto outros defendem que qualquer expressão formal tem um significado referencial a ser levado em conta.

Essa polêmica não é trivial e tem influenciado o ensino de Matemática. As concepções formalistas conduzem ao ensino baseado muito mais na manipulação sintática de símbolos e regras do que no significado dos mesmos. Uma alternativa para isso são as tendências denominadas conceituais ou semânticas, segundo as quais a prioridade está no estudo dos aspectos conceituais da Matemática, segundo a qual é importante que os estudantes entendam ou construam o significado dos conceitos.

Uma possibilidade nessa segunda alternativa é o uso de jogos, que pode levar os estudantes a atribuir significado a conceitos através da "[...] compreensão, apreensão, desenvolvimento, explicitação e formação de conceitos" (GRANDO, 2007, p.51).

Um dos aspectos essenciais para o sucesso de uma proposta educacional que faça uso de jogos digitais refere-se aos atributos que incidem no nível de motivação que os estudantes apresentam em situações de aprendizagem. Nesse sentido, a teoria de Keller, situada entre as filosofias construtivista e cognitivista, parece ser adequada para investigar aspectos motivacionais que acontecem no processo educativo que faz uso de jogos digitais. O modelo proposto por Keller (2000) é denominado ARCS (Attention, Relevance, Confidence, Satisfaction) e possui quatro componentes chave: Atenção (A), Relevância (R), Confiança $(C)$ e Satisfação (S). Esses quatro elementos representam um conjunto de condições necessárias para uma pessoa ser totalmente motivada pelo processo de aprendizagem.

No que tange à motivação para aprender Matemática, Middleton e Spanias (1999) postulam que os estudantes tendem a organizar suas construções mentais em três categorias gerais: excitação, ou a estimulação cognitiva proporcionada por uma atividade; controle pessoal, ou o grau em que a atividade foi considerada uma escolha livre ou de dificuldade apropriada; interesses, ou o grau em que os estudantes gostaram da atividade, a importância da atividade, e sua habilidade em executá-la. As duas primeiras categorias estão intimamente relacionadas com a atenção despertada por uma atividade educativa, desse modo, a atividade deve atrair o estudante 
e mantê-lo atento. Atrair e manter a atenção do jogador para garantir a motivação é matéria prima para a concepção de jogos digitais. Nesse sentido, muitos jogos vêm sendo criados com o objetivo de auxiliar o estudante no processo de aprendizagem de Matemática, mas garantindo também o divertimento e a imersão. Esses jogos fazem uso de recursos lúdicos para prender a atenção do jogador, apresentando desafios que contemplam conceitos de Matemática, além de apresentarem bônus de informação sobre os referidos conceitos. (SOBRINHO et. al, 2016)

O uso de situações problema desafiadoras, como as existentes nos jogos digitais, pode levar os estudantes a perceber a relevância da Matemática, aprenderem novos conteúdos, e não apenas aplicarem aqueles que já conhecem. À medida que buscam soluções para os obstáculos e desafios dos jogos podem procurar relações, analisar padrões, descobrir métodos, justificar resultados, avaliar e desafiar os raciocínios dos outros, refletindo sobre ideias envolvidas (VAN DER VALLE, 2009). Isso pode leva-los a entender a utilidade e importância da Matemática. (MIDDLETON; SPANIAS, 1999).

Partindo desses pressupostos propôs-se um estudo com o objetivo de desenvolver e avaliar o potencial um Jogo Digital Educativo que ofereça suporte para atividades pedagógicas com vistas à aprendizagem de conteúdos de Matemática do Ensino Fundamental e Médio, indispensáveis para o desenvolvimento da disciplina Cálculo Diferencial e Integral. Com a realização deste estudo, pretende-se responder à seguinte questão: Quais os elementos técnicos e fundamentos pedagógicos necessários para o desenvolvimento de um Jogo Digital Educativo que seja um recurso educacional para aprendizagem de conteúdos de Matemática do Ensino Fundamental e Médio?

$\mathrm{Na}$ intenção de responder à essa questão, foram definidos os seguintes objetivos específicos: definir os critérios que visam garantir a colaboração entre a equipe técnica (estudantes do curso Superior de Tecnologia em Jogos Digitais) e pedagógica (professores de Matemática) no desenvolvimento de um Jogo Digital Educativo que motive a aprendizagem de Matemática; identificar quais recursos de jogabilidade devem ser criados em um Jogo Digital Educativo para dar suporte à aprendizagem de conteúdos de Matemática; identificar os aspectos pedagógicos que deverão ser contemplados no Jogo Digital Educativo; eleger os conteúdos de Matemática para a construção do Jogo Digital Educativo entre as seguintes temáticas: funções, frações, fatoração e manipulações algébricas; desenvolver e avaliar o potencial do Jogo Digital Educativo.

\section{METODOLOGIA}

A busca pela compreensão de quais elementos técnicos e fundamentos pedagógicos são necessários para o desenvolvimento de um Jogo Digital Educativo para a aprendizagem de conteúdos de Matemática do Ensino Fundamental e Médio, levou os pesquisadores a optarem por uma abordagem metodológica que se preocupasse com o contexto e com a forma pela qual este contexto influencia as variáveis de uma pesquisa. Isso posto, foi escolhida a abordagem qualitativa, por ser descritiva, ou seja, tudo que faz parte do contexto pode ser descrito e oferecer elementos para esclarecer pontos do objeto de estudo (BOGDAN; BIKLEN, 1994)

Quanto ao levantamento de dados, o estudo faz uso da técnica da observação participante, que permite uma participação intensa dos pesquisadores no reconhecimento das variáveis técnicas e pedagógicas no processo de desenvolvimento do Jogo Digital Educativo, observando suas reações aos estímulos e suas formas de adaptação (MICHALISZYN; TOMASINI, 2007). Os pesquisadores observaram e registraram os elementos técnicos e os fundamentos pedagógicas necessários para o planejamento, desenvolvimento e testes do Jogo Digital Educativo (ALVESMAZZOTTI; GEWANDSZNAJDER, 1999; LAKATOS; MARCONI, 1985).

Para o desenvolvimento do estudo foram consideradas as seguintes etapas: planejamento do Jogo Digital Educativo em termos de estabelecer os requisitos técnicos e pedagógicos que 
deverão ser contemplados em seu desenvolvimento; implementação de um protótipo de um Jogo Digital Educativo para a aprendizagem de conteúdos de Matemática; testes para o levantamento de dados referentes às interações dos professores de Cálculo Diferencial e Integral com o Jogo Digital Educativo; e análise dos dados coletados para subsidiar a manutenção do Jogo Digital Educativo.

O jogo será testado do ponto de vista técnico (usabilidade e jogabilidade), bem como do ponto de vista pedagógico no tocante ao seu potencial para ser utilizado em um ambiente educacional. Para tanto, serão entrevistados dois professores voluntários para fazer uso do jogo e emitir impressões sobre seu potencial para a aprendizagem de conteúdos de Matemática contemplados pelo jogo. A entrevista clínica foi escolhida em razão do número de participantes e por fornecer subsídios mais substanciais uma vez que cada resposta dos entrevistados às questões do roteiro de entrevista pode gerar elementos para uma outra pergunta, aprofundando e enriquecendo o levantamento de dados sobre o jogo. O roteiro para a realização dos testes do jogo está baseado em três eixos: Motivação a partir do Modelo ARCS, Experiência do Usuário e Conhecimento.

A análise final dos dados será realizada por meio de categorias de análise que serão criadas a partir das observações registradas e dos resultados dos testes de usabilidade e jogabilidade, à luz da teoria estudada.

\section{RESULTADOS}

Para viabilizar o processo de desenvolvimento, a criação do jogo foi desmembrada em duas etapas. A primeira consistiu na definição dos planos, cenários, terreno, entre outras características do jogo, além do incremento de estilo, sinopse e jogabilidade. Foi definido que o jogo teria início a partir de uma plataforma que permite ao jogador escolher via portal qual ambiente será vivenciado. Em cada um desses ambientes o jogador terá acesso a situações didáticas envolvendo diferentes conteúdos matemáticos.

Desenvolvido em ambiente 3D, o jogo está sendo produzido com a utilização de mecânica com câmera em ângulo direito e inclinação de 50 na vertical e 360 na horizontal, textura aplicada à realidade do cenário, possibilitando melhor jogabilidade e qualidade visual. Sua elaboração ocorreu mesmo com as limitações do software de desenvolvimento Unity na medida em que, ao restringir algumas funções, oportunizou a busca de recursos adicionais a fim de atingir o que foi proposto.

A escolha do roteiro com tema de fantasia medieval ocorreu dada a tendência dos jogos atuais. Os cenários e objetos 3D foram desenvolvidos em imagens Low Poly (baseadas em polígonos) com características cartunescas, com pouco realismo para agilizar o andamento da programação. Na criação foi utilizado sistema click com as características vetoriais de mobilidade na plataforma, e para promover maior imersão foi utilizado o recurso de Raycast onde cada frame é identificado pelo mesmo quando houver a colisão. A interação do jogador foi planejada de maneira que ele se envolva com a temática proposta, aliando diversão e aprendizagem de conteúdos matemáticos de forma agradável e eficiente.

O ambiente do jogo contempla ações em que o jogador será primeiramente levado a ao cenário de um antigo galpão abandonado com alguns equipamentos em desuso. No galpão há uma plataforma que possui um painel que disponibiliza três botões que são responsáveis por selecionar três cenários diferentes. Quando o jogador interagir com o painel, uma porta ao fundo da sala será ativada e um "portal" permitirá ao jogador vivenciar situações em diferentes épocas da humanidade, sendo proposto a ele problemas que envolvam conteúdos matemáticos (Figura 1). 
Figura 1. À esquerda plataforma com 3 opções e à direita o cenário escolhido a partir do botão 3.

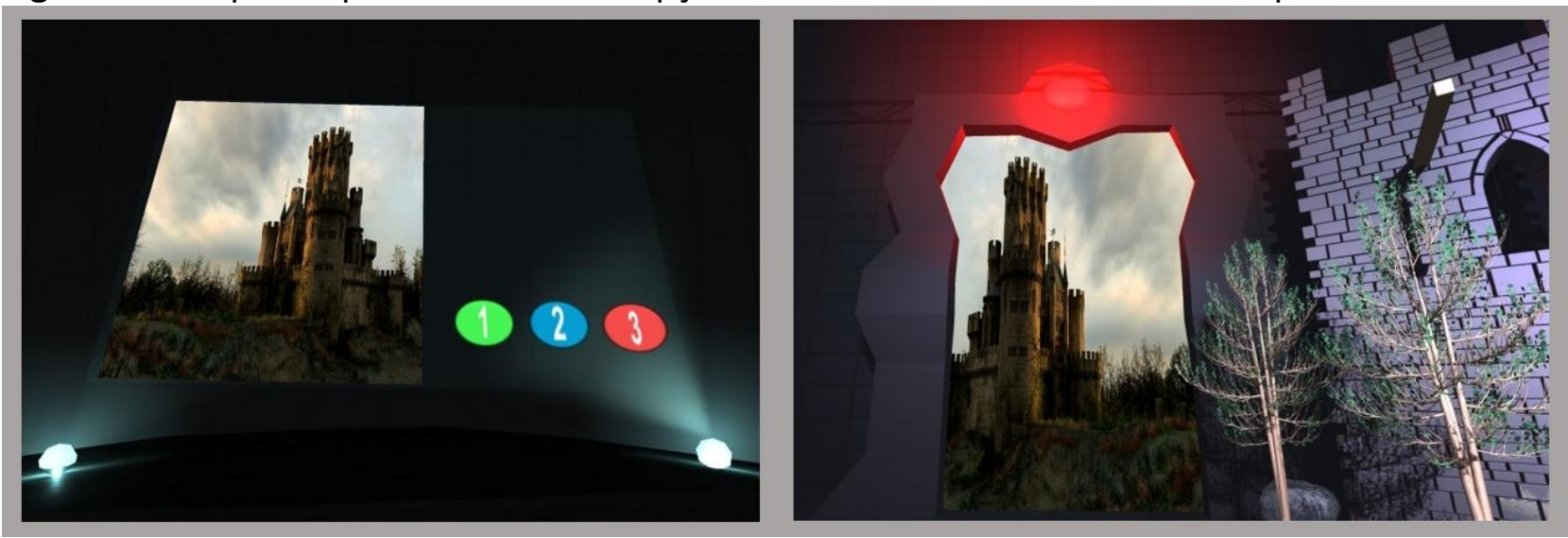

Fonte: Os autores.

Na segunda etapa de desenvolvimento do jogo, o foco será na criação do ambiente a que o jogador terá acesso após atravessar o portal. Um dos portais, por exemplo, levará o jogador à segunda metade do século XII, na França, em uma feira de um burgo, na qual ele tem a oportunidade de vivenciar relações de compra e venda de produtos, nas quais está subjacente o conceito de função. À medida em que o jogador transita entre as épocas (portais), é desafiado a partir de situações problema que oportunizam a apropriação de conteúdos matemáticos. 0 ambiente do jogo oferecerá ao jogador a possibilidade de abrir outros portais, por meio dos quais ele terá contato com notáveis pensadores da época, como por exemplo, Newton e Einstein, e as suas contribuições para o desenvolvimento da Matemática.

\section{DISCUSSÃO}

Os próximos passos do desenvolvimento do jogo estabelecerão os critérios de implantação e aplicação dos conteúdos matemáticos, com o cuidado de comtemplar a questão do divertimento e manter o jogador em estado de fluxo no ambiente, promovendo a fluidez que propicia a relação entre aprendizagem e diversão.

O conceito de jogo transcende o ato de brincar, é acompanhado de elementos que estabelecem relações mais amplas entre os indivíduos envolvidos a partir de suas regras, da motivação para vencer, da estabilidade para reconhecer as derrotas e aprender com elas. A esses elementos subjetivos associados aos jogos, somam-se também elementos técnicos responsáveis por tornar tangível as relações entre os indivíduos e a representação da realidade.

Para Huizinga (2000, p. 14), a representação da realidade em um ambiente de jogo permite que a criança ou adolescente possa ficar literalmente "transportada(o)" de prazer, superando-se a si mesmo a tal ponto que quase chega a acreditar que realmente é esta ou aquela coisa, sem perder inteiramente o sentido da "realidade habitual". Mais do que uma realidade falsa, sua representação é a realização de uma aparência: é "imaginação", no sentido original do termo.

\section{CONCLUSÃO}

O processo de desenvolvimento do jogo digital enfocou aspectos como a modelagem tridimensional dos objetos do cenário e a criação da interface por meio da qual o jogador terá acesso ao ambiente em que se desenrolará a jogabilidade. Nesta fase do jogo, a perspectiva gráfica da câmera está definida em primeira pessoa, ou seja, o cenário é explorado pelo ponto de vista do personagem controlado pelo jogador. Em trabalhos futuros, será apresentado o universo no qual o jogo funcionará, contemplando a criação do cenário medieval, as características do personagem e as regras e desafios que serão propostos na jogabilidade que abordará os conteúdos da matemática, para essa fase do jogo a perspectiva da câmera será criada em terceira 
pessoa.

Pesquisas recentes têm revelado que o ensino aliado ao uso das tecnologias digitais é a tendência das práticas pedagógicas atuais devido ao perfil dos estudantes contemporâneos, que estão constantemente em contato com os ambientes digitais. No caso específico dos jogos digitais, de modo a possibilitar a aprendizagem, seu uso deve transcender o brincar. Para tanto, devem ser planejados no sentido de buscar a imersão dos estudantes, levando-os a se manterem motivados nas situações envolvidas nos jogos, levando em conta o equilíbrio da relação entre diversão e aprendizagem de conteúdos escolares. A busca por tal equilíbrio norteou todo processo de desenvolvimento do jogo até o momento.

\section{REFERÊNCIAS}

ALVES-MAZZOTTI, A. J.; GEWANDSZNAJDER, F. O método nas ciências naturais e sociais: pesquisa quantitativa e qualitativa. São Paulo: Pioneira, 1999.

BOGDAN, R. C.; BIKLEN, S. K. Investigação Qualitativa em Educação. Porto, Portugal: Porto Editora, 1994.

GRANDO, R. C. Concepções quanto ao uso de jogos no ensino da Matemática. Revista de Educação Matemática, v. 10, p. 45-52, 2007.

HUIZINGA, J. Homo Ludens: o jogo como elemento da cultura. 6. ed. São Paulo: Perspectiva, 2000.

HOED, R. M. Análise da evasão em cursos superiores: o caso da evasão em cursos superiores. 2016. 188 p. Dissertação (Mestrado - Mestrado Profissional em Computação Aplicada) -Universidade de Brasília, 2016.

KELLER, J. M. How to integrate learner motivation planning into lesson planning: The ARCS model approach. Conference proceedings: VII Semanario, Santiago, Cuba. 2000. Disponível em: http://apps.fischlerschool.nova.edu/toolbox/instructionalproducts/itde8005/weeklys/2000-KellerARCSLessonPlanning.pdf. Acesso em: 18 out. 2016.

LAKATOS, E. M.; MARCONI, M. de A. Fundamentos da Metodologia Científica. São Paulo: Atlas, 1985.

MIDDLETON, J. A; SPANIAS, P. A. Motivation for achievement in mathematics: Findings, generalizations, and criticisms of the research. Journal for Research in Mathematics Education, 30 (1), 65-88. $1999 . \quad$ Disponível em: http://mathedseminar.pbworks.com/w/file/fetch/51227989/MotivationFull.pdf. Acesso em: 18 nov. 2017.

SAVI, R.; VON WANGENHEIM, C. G.; ULBRICHT, V.; VANZIN, T. Proposta de um Modelo de Avaliação de Jogos Educacionais. RENOTE - Revista Novas Tecnologias na Educação.v. 8, n. 3, dez. 2010. Disponível em: http://seer.ufrgs.br/index.php/renote/article/view/18043/10630. Acesso em: 23 nov. 2017.

SOBRINHO, M. E.; RESPLANDES, D. C. da S.; VALENTE, K. W. S.; NETO, E. S.; FILHO, M. R. Game Serra Pelada: Projeto Implementação e Avaliação de um Jogo Educativo para o ensino de Geometria para Estudantes do $9^{\circ}$ do Ensino Fundamental. XV SBGames - São Paulo - SP - Brazil, September 8th - 10th, 2016.2 Disponível em: 
http://www.sbgames.org/sbgames2016/downloads/anais/157208.pdf. Acesso em: 15 nov. de 2017.

VAN DER WALLE, J. A. Matemática no ensino fundamental: formação de professores e aplicação em sala de aula. 6. ed. Porto Alegre: Artmed, 2009. 